\title{
Fungal Endophyte Communities in Begonia Species from the Brazilian Atlantic Rainforest
}

\author{
Ana M. L. Correia ${ }^{1}$ Simone P. Lira ${ }^{2} \cdot$ Marco A. Assis $^{3} \cdot$ Andre Rodrigues $^{1}(1)$
}

Received: 8 May 2017 / Accepted: 15 November 2017 / Published online: 20 November 2017

(c) Springer Science+Business Media, LLC, part of Springer Nature 2017

\begin{abstract}
Tropical plants represent hotspots of endophytic fungal species diversity. Based on culture-dependent methods, we evaluated the endophytic fungal communities in leaves of three plant species found in the Brazilian Atlantic Rainforest: Begonia fischeri, Begonia olsoniae, and Begonia venosa. These species are found in two distant sites: a continental region and an insular area. A total of 426 fungal endophytes in 19 genera were isolated in pure culture including Colletotrichum (51.6\% of isolates) and Diaporthe (22.5\%) as the most abundant, followed by Phyllosticta (3.5\%), Neopestalotiopsis (1.8\%), Stagonospora (1.8\%), and Nigrospora (1.6\%) among the genera found in minor abundance. The diversity and composition of fungal taxa differed across plant hosts. Richness and diversity of fungi were higher in B. fischeri in comparison to B. olsoniae and $B$. venosa. Discriminatory analysis revealed that fungal communities are structured according to hosts, which means that each plant species had its distinct endophytic communities, but dominated by common fungal taxa. This is the first study to report fungal endophytes in begonia leaves and characterize their communities.
\end{abstract}

Keywords Fungus-plant interaction $\cdot$ Diversity $\cdot$ Begoniaceae $\cdot$ Endophytic

\section{Introduction}

Endophytic microorganisms live within plant tissues without causing any disease symptoms $[1,59]$. These microbes may contribute to the nutrition, growth, and resistance of hosts against pathogens [2]. Considered a hyper-diverse group, endophytes also represent an important source of new bioactive metabolites [47, 58].

Endophytic microorganisms are widely distributed among terrestrial plants. It is thought that each plant species harbors at least one endophytic fungus species, however, this

Electronic supplementary material The online version of this article (https://doi.org/10.1007/s00284-017-1400-1) contains supplementary material, which is available to authorized users.

Andre Rodrigues

andrer@rc.unesp.br

1 Department of Biochemistry and Microbiology, Institute of Biosciences, São Paulo State University (UNESP), Av. 24-A, n 1515, Bela Vista, 13506-900 Rio Claro, Brazil

2 Department of Exact Sciences, Luiz de Queiroz College of Agriculture, Piracicaba, Brazil

3 Department of Botany, Institute of Biosciences, São Paulo State University (UNESP), Rio Claro, Brazil number can vary from tens to hundreds, depending on the host [2]. Several studies covering the geographical distribution of plant hosts and their associated endophytic community unraveled distribution patterns of these interactions $[3,9,51,60]$. These studies clearly showed that a myriad of interactions occur between hosts and endophytes (ranging from specific to generalist), as well as among endophytes within the same host [42].

Begonia is one of the largest genus of vascular plants, comprehending about 1500 species [23], distributed throughout the tropical zones [18]. Of the 213 species that occur in Brazil, 186 are endemic of the Atlantic Rainforest [25]. Begonia species were target of several studies as indicators of biogeographic variation, population analysis of endemic species, hybridization, and genomics, among others $[10,11]$. Some studies point to the biotechnological potential of Begonia malabarica Lam. in the treatment of diabetes [36]. In addition, leaf extracts of the same species presented antimicrobial activity against the bacteria Pseudomonas aeruginosa, Staphylococcus aureus, and Klebsiella pneumoniae [41]. However, no study examined the association of endophytic microorganisms with Begonia species.

It is known that tropical plants represent hotspots of fungal species diversity [3] because such plants harbor 
a great diversity of endophytes that are promising for applied studies [46]. For this reason, we focused on three begonia species: Begonia venosa Skan ex Hook. f. found only on the north coast islands of São Paulo State. On the other hand, Begonia olsoniae L.B. Sm. \& B.G. Schub. is only found in the continental region of southeastern Brazil. Yet, Begonia fischeri Schrank is found in all Brazilian biomes and also occurring from the Antilles to Argentina [26]. These species occur in different habitats, but were found in the same biome, which is interesting for endophyte diversity studies. $B$. venosa occurs in low slope areas with high accumulation of organic matter, such as hilltops and rock crevices. On the other hand, $B$. olsoniae is rupicolous and preferably occurs in shaded areas, while B. fischeri has a terrestrial habitat and occurs mainly in sites with high incidence of light and moist soils, usually in disturbed or in regeneration areas $[26,56]$.

The distribution of endophytic fungi across terrestrial plants is an intriguing question. In an attempt to expand the knowledge about this group of fungi, we profiled the endophytic fungal communities associated with: B. fischeri, $B$. olsoniae, and $B$. venosa founded in the same biome but in different areas (island and continent) and habitats to understand their composition, structure, and diversity.

\section{Materials and Methods}

\section{Study Areas and Sampling}

The present study was conducted at two sites: (i) on the continent, in the municipality of Ubatuba and (ii) on the Alcatrazes Island, in the municipality of São Sebastião, both located on the northern coast of São Paulo State. The Alcatrazes Island is located near four other islands, making up the Alcatrazes Archipelago, located $43 \mathrm{~km}$ off the Brazilian coast.

We carried out two expeditions: the first was held on the continental area in June 2014, in Parque Estadual da Serra do Mar, Ubatuba, SP, Brazil. A total of five specimens of $B$. fischeri and five of B. olsoniae were collected (Table S1). The specimens were placed in plastic bags and stored under refrigeration until processing, which was carried out on the same day of collection. The second expedition was held in February 2015 on Alcatrazes Island. Five specimens of $B$. venosa were found, collected, and transported as described (Table S1).

Mature individuals of all species were collected as vouchers for identification. The vouchers were taken to the Herbário Rioclarense (HRCB) of UNESP, Rio Claro, SP, as HRCB 64226 (B. fischeri), HRCB 64227 (B. venosa), and HRCB 64229 (B. olsoniae).

\section{Isolation of Endophytic Fungi}

Four healthy leaves were selected from each plant specimen; then a total of 60 leaves were examined considering all specimens of the three Begonia species. The leaves were first washed with tap water to remove soil particles and other detritus. Subsequently, the leaves were submerged for $1 \mathrm{~min}$ in sterile distilled water, followed by $1 \mathrm{~min}$ in $70 \%$ ethanol, $2 \mathrm{~min}$ in $2.5 \% \mathrm{NaOCl}, 1 \mathrm{~s}$ in $70 \%$ ethanol, and $2 \mathrm{~min}$ in sterile distilled water [39]. To check the efficiency of the disinfection process, $100 \mu \mathrm{L}$ of the final washing batch was plated on malt agar 2\% (MA2\%) and incubated at $25{ }^{\circ} \mathrm{C}$ for 15 days. After disinfection, each leaf was cut into fragments $(0.8-1.0 \mathrm{~cm})$ with a flame-sterilized scalpel. Five fragments of each leaf were inoculated on the surface of potato dextrose agar plates (PDA-Acumedia, nutrient-rich medium). Thus, 20 leaf fragments were analyzed for each of the 15 Begonia specimens in PDA. The remaining fragments were cut into several smaller pieces, placed in sterilized empty Petri dishes, and then malt agar $2 \%$ was poured on the leaves (MA2\%-Acumedia, intermediate-nutrient medium). Both media were supplemented with tetracycline $\left(100 \mathrm{mg} \mathrm{L}^{-1}\right)$ and streptomycin sulfate $\left(20 \mathrm{mg} \mathrm{L}^{-1}\right)$ to prevent bacterial growth.

Isolation plates were incubated at $25{ }^{\circ} \mathrm{C}$ for 10 days in darkness and observed daily. Fungal colonies were transferred to MA2\% plates and incubated under the same conditions to obtain pure cultures. Monosporic cultures were prepared from fungi that presented sporulation. For those fungi that did not sporulate, axenic cultures were prepared by successive transfers in MA2\%. Cultures are maintained in MA2\% agar slants at $10{ }^{\circ} \mathrm{C}$ and in $10 \%$ glycerol at $-80{ }^{\circ} \mathrm{C}$. Isolates are deposited in the fungal collection of UNESP-Microbial Resources Center.

\section{Fungal Identification}

Fungal isolates were grouped into morphospecies and characterized based on general aspects of the colony and microscopic observations of the reproductive structures. Microscopic preparations were made from fresh mycelium using water or cotton blue as mounting fluid. The observed structures were compared with those found in taxonomic keys $[14,15]$. Genomic DNA from representative strains of all morphospecies was extracted and submitted to ITS sequencing with primers ITS4 and ITS5 [7, 44]. However, for some taxa we amplified and sequenced additional DNA regions to obtain better taxonomic resolution as follows: for Aspergillus and Penicillium, we amplified the beta tubulin gene (with primers $\beta T 2 a$ and $\beta T 2 b$ ); for 
Trichoderma we amplified and sequenced the elongation factor alpha gene (with primers tef1r and 728F). Amplification reactions and conditions were those described in Montoya et al. [32].

The amplicons were visualized in $1 \%$ agarose gel stained with GelRed ${ }^{\circledR}$ (Biotium) after electrophoresis. Then, amplicon purification was performed with Wizard ${ }^{\circledR}$ Genomic DNA Purification Kit (Promega) and quantified in NanoDrop (Thermo Scientific). An amount of $20 \mathrm{ng}$ of DNA was used as template in cycle sequencing reactions using BigDye $^{\circledR}$ Terminator Cycle Sequencing Kit v. 3.1 (Life Technologies), following the manufacturer's protocol. After bidirectional sequencing in ABI 3500 (Life Technologies), contigs were assembled in BioEdit v. 7.0.5.3 [19] and compared with homologous sequences deposited in the NCBIGenBank. Sequences belonging to the genus Trichoderma were compared with those deposited in the International Subcommission database on Trichoderma and Hypocrea Taxonomy (ISTH) using TrichOKEY [13].

Sequences were grouped into molecular operational taxonomic units (MOTUs) in MOTHUR, considering a cutoff of $97 \%$ similarity [43]. Phylogenetic trees were inferred to assist in the fungal taxonomic affiliation of some groups namely, Aspergillus, Colletotrichum, Diaporthe, Epicoccum, Mucor, Penicillium, Stemphylium, and Trichoderma (Figures S1-S8). These analyses were conducted with sequences obtained from the NCBI-GenBank as well as sequences obtained from several studies [5, 12, 16, 24, 50, 55, 57]. Sequences were aligned in MAFFT [27] and the phylogeny was inferred using the neighbor-joining method under the Kimura 2-parameter model [28]. Branch support values were calculated with 1000 bootstrap replicates using MEGA v. 6.0 [49]. Sequences of accession numbers used in all phylogenetic analyses are listed in Table S2.

\section{Analysis of Endophyte Communities}

We estimated the fungal richness for each community using the Chao1 estimator [31]. Rarefaction curves were generated to compare the observed richness of fungal taxa between plant species. Moreover, the Simpson (1/D) and Shannon diversity indices were calculated. To determine the number of shared species we used the Jaccard, Sorensen, and Bray-Curtis indices [31]. To check which taxa accounted for the observed differences among samples, we carried out a percentage of similarity analysis (SIMPER) in Past v. 2.17c using the Bray-Curtis distance [6]. Rarefaction curves and all the indices were calculated in EstimateS v.9.1.0 [8]. To verify significant differences between the indices, we used Kruskal-Wallis test in R v. 3.0.1. In addition, the number of fungal taxa and the unique species found in each plant species were represented in a Venn diagram.
To investigate the relationship between fungal communities and plant hosts, a correspondence analysis (CA) was performed in Past v. 2.17c [20]. In this analysis, we used the Bray-Curtis distance considering the abundance of fungi found in each plant species. This dissimilarity index was calculated from each pair of host plants. A dissimilarity matrix was generated which was used for mapping the interrelation between plants and fungal abundance [40].

\section{Results}

\section{Diversity of Endophytic Fungi in Begonia Species}

We evaluated 60 leaves (20 of each of the three Begonia species), all of which were positive for endophytes. No fungal growth was observed in the control plates inoculated with leaf washings, indicating the disinfection process was effective in eliminating epiphytic microorganisms. A total of 426 fungal isolates were obtained: 120 from $B$. fischeri, 151 from $B$. olsoniae, and 155 from B. venosa in both culture media. Based on morphological characters, the 426 isolates were grouped into 71 morphospecies. Representative isolates ( $n=302$ out of 426 isolates) of each morphospecies were sequenced. Then, the sequences were grouped into 46 MOTUs, comprising the phyla Ascomycota (93.5\% of the 426 isolates), Basidiomycota (4.3\%), and Mucoromycotina (2.2\%). For representatives of the phylum Ascomycota, nine orders were found: Botryosphaeriales, Capnodiales, Diaporthales, Eurotiales, Hypocreales, Pleosporales, Sordariales, Trichosphaeriales, and Xylariales. The phylum Basidiomycota was represented by two isolates: one belonging to the Cantharellales order and one unidentified isolate. Only one isolate of the Mucoromycotina was recovered, which belongs to the Mucorales order (Figures S1-S9 and Table 1).

Among the 46 MOTUs, 19 genera were identified including Colletotrichum (51.6\% of the 426 isolates) and Diaporthe (22.5\%) as the most abundant (Table 1). All plants exhibited as dominant genera Colletotrichum and Diaporthe. Specifically, B. fischeri had Colletotrichum sp3 (20\%) and Diaporthe sp1 (11.6\%) as the most abundant MOTUs. In $B$. olsoniae leaves we found Colletotrichum sp1 (53.6\%) and Diaporthe sp1 (12.5\%), whereas B. venosa had Colletotrichum sp2 (34\%) and Diaporthe sp3 (14\%). The latter fungus was found only in $B$. venosa. Sequences that exhibited low similarity $(<97 \%)$ with those available in the databases belonging to isolates that could not be identified by morphology are presented as unidentified Ascomycota or Basidiomycota (Table 1 and Table S2).

None of the rarefaction curves reached an asymptote, suggesting that richness of fungal taxa would continue to increase with the sampling effort (Figure S10). In addition, the estimated richness (Chao1) of fungal taxa was similar 
Table 1 Distribution of 46 MOTUs of endophytic fungi obtained from Begonia fischeri, Begonia olsoniae, and Begonia venosa collected in the Atlantic Rainforest

\begin{tabular}{|c|c|c|c|c|}
\hline Taxa & B. fischeri & B. olsoniae & B. venosa & Total \\
\hline Aspergillus niger Tiegh. & 3 & & & 3 \\
\hline Aspergillus sp. & 1 & & & 1 \\
\hline Bartalinia sp. & & & 1 & 1 \\
\hline Cantharellales & 1 & & & 1 \\
\hline Cladosporium sp. & 3 & & & 3 \\
\hline Colletotrichum sp1 & 13 & 81 & 2 & 96 \\
\hline Colletotrichum sp2 & 12 & 6 & 53 & 71 \\
\hline Colletotrichum sp3 & 24 & 7 & 14 & 45 \\
\hline Colletotrichum sp4 & & 7 & & 7 \\
\hline Colletotrichum sp5 & & 1 & & 1 \\
\hline Curvularia sp1 & 3 & & & 3 \\
\hline Curvularia sp2 & 1 & & & 1 \\
\hline Diaporthe sp1 & 14 & 19 & 21 & 54 \\
\hline Diaporthe sp2 & & & 11 & 11 \\
\hline Diaporthe sp3 & & & 22 & 22 \\
\hline Diaporthe sp4 & & 5 & & 5 \\
\hline Diaporthe sp5 & 1 & & & 1 \\
\hline Diaporthe sp6 & & 1 & & 1 \\
\hline Diaporthe sp7 & 1 & & & 1 \\
\hline Diaporthe sp8 & & 1 & & 1 \\
\hline Endomelanconiopsis sp. & & 3 & & 3 \\
\hline Epicoccum nigrum Link & 2 & 1 & & 3 \\
\hline Mucor bainieri B.S. Mehrotra \& Baijal & & 1 & & 1 \\
\hline Neofusicoccum sp. & & & 5 & 5 \\
\hline Neopestalotiopsis sp. & 8 & & & 8 \\
\hline Neurospora sp. & & 2 & & 2 \\
\hline Nigrospora sp. & 6 & 1 & & 7 \\
\hline Penicillium thomii var. flavescens S. Abe & 4 & & & 4 \\
\hline Phoma sp. & & & 2 & 2 \\
\hline Phyllosticta sp. & & & 15 & 15 \\
\hline Pleosporales & 6 & 2 & & 8 \\
\hline Stagonospora sp. & 8 & & & 8 \\
\hline Stemphylium sp. & & & 1 & 1 \\
\hline Trichoderma atroviride P. Karst & & & 2 & 2 \\
\hline Trichoderma sp. & & 1 & & 1 \\
\hline Xylariales 1 & 1 & 1 & 2 & 4 \\
\hline Xylariales 2 & 2 & 1 & & 3 \\
\hline Xylariales 3 & 2 & & & 2 \\
\hline Xylariales 4 & 1 & & 1 & 2 \\
\hline Xylariales 5 & 1 & & & 1 \\
\hline Xylariales 6 & 1 & & & 1 \\
\hline Unidentified ascomycota 1 & & 10 & & 10 \\
\hline Unidentified ascomycota 2 & & & 1 & 1 \\
\hline Unidentified ascomycota 3 & & & 1 & 1 \\
\hline Unidentified ascomycota 4 & 1 & & & 1 \\
\hline Unidentified basidiomycota & & & 1 & 1 \\
\hline Total & 120 & 151 & 155 & 426 \\
\hline
\end{tabular}

Figures represent the number of isolates recovered using culture-dependent methods 

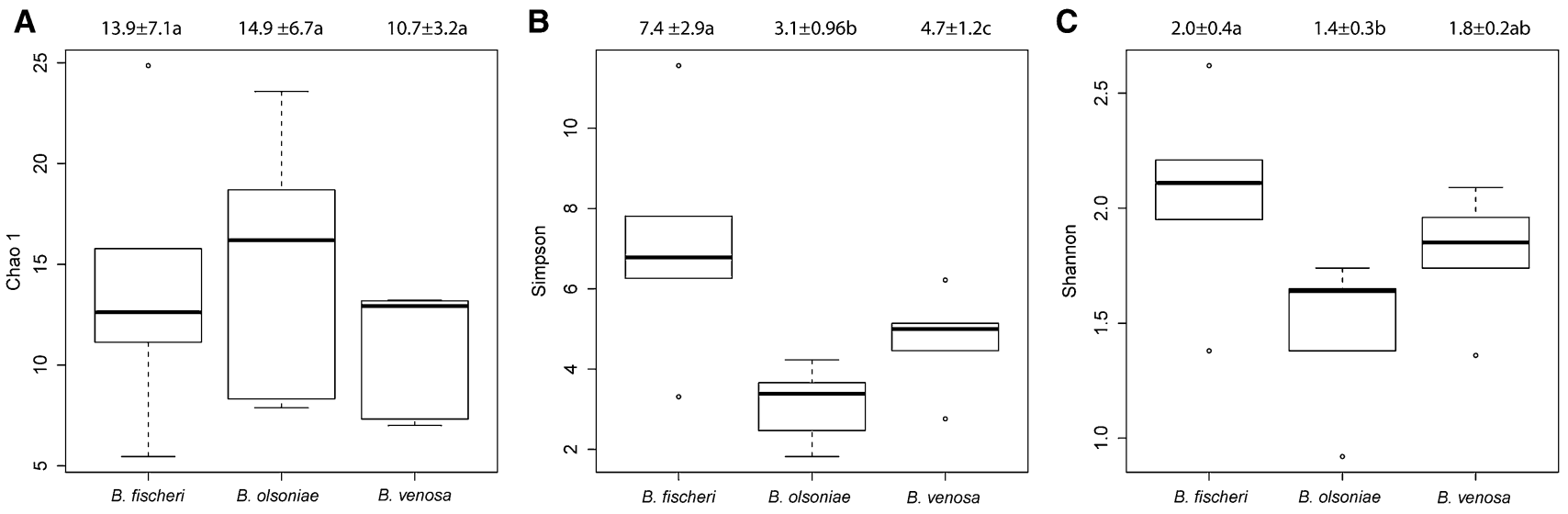

Fig. 1 Estimated species richness (Chao1) and diversity indices (Simpson and Shannon) of endophytic fungi found in Begonia fischeri, Begonia olsoniae, and Begonia venosa. The mean and standard

Table 2 Indices of shared taxa between fungal communities of three Begonia species found in the Atlantic Rainforest

\begin{tabular}{lllll}
\hline Plants & & Jaccard & Sorensen & Bray-Curtis \\
\hline B. fischeri & B. olsoniae & 0.257 & 0.409 & 0.339 \\
B. fischeri & B. venosa & 0.167 & 0.286 & 0.32 \\
B. olsoniae & B. venosa & 0.161 & 0.278 & 0.229 \\
\hline
\end{tabular}

between plant species (Kruskal-Wallis, $P>0.1$, Fig. 1a), indicating that it is expected to find more rare species in similar proportions in all three plant species.

According to the Simpson diversity index, communities of endophytes in B. fischeri, B. olsoniae, and B. venosa significantly differed (Kruskal-Wallis, $P>0.1$, Fig. 1b). In addition, differences in diversity were found between fungal communities of $B$. fischeri and B. olsoniae that exhibited the highest and the lowest diversity of fungi, respectively (Fig. 1b). These differences accounted for Colletotrichum sp1 (81 isolates), which was the dominant fungus found in B. olsoniae and that influenced the results of the Simpson index. On the other hand, B. venosa, the endemic species, showed no significant differences in diversity in comparison to the non-endemic Begonia species (Fig. 1c).

\section{Structure and Composition of Endophyte Communities}

Plant hosts shared few fungal taxa as indicated by indices below 0.5 (Table 2). These results corroborate with those obtained in the SIMPER analysis, which demonstrated that endophyte communities have an overall difference of $77.16 \%$. From this dissimilarity, Colletotrichum sp1 accounted for $24.58 \%$ of the difference, which shows the importance of this taxon for all communities. In addition, deviation of the indices are provided above each boxplot. Similar letters indicate no significant differences (Kruskal-Wallis, $P>0.1$ ). Circles indicate outliers. a Chao1, b Simpson, c Shannon

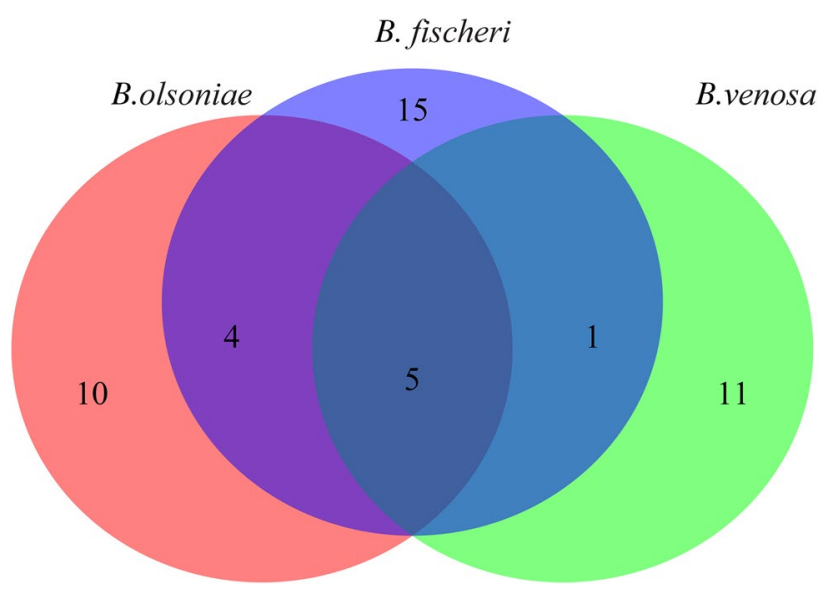

Fig. 2 Venn diagram indicating the number of shared and rare fungal taxa among Begonia fischeri, Begonia olsoniae, and Begonia venosa

the pairwise analysis showed that $B$. fischeri and $B$. venosa exhibited $74 \%$ dissimilarity. From this total, Colletotrichum sp2 and Diaporthe sp3 accounted for 15 and $8 \%$ of the overall difference, respectively. Moreover, $B$. venosa and B. olsoniae differed by $83.6 \%$, and the taxa Colletotrichum sp1 and Colletotrichum sp2 accounted for 25.9 and $15 \%$ of this difference, respectively. Finally, B. fischeri and B. olsoniae differed by $73.8 \%$, with the expressive collaboration of Colletotrichum sp1 (26.8\%) and Colletotrichum sp3 (6.9\%) for the dissimilarity.

A total of five taxa (Colletotrichum sp1, Colletotrichum sp2, Colletotrichum sp3, Diaporthe sp1, and Xylariales 1) were found in all three Begonia species, representing 270 isolates from the total of 426 . Furthermore, B. fischeri and $B$. olsoniae shared four taxa, which were not shared by B. venosa (Epicoccum nigrum Link, Nigrospora sp., Pleosporales, and Xylariales $2 ; n=21$ isolates). However, only 
one taxa (Xylariales $4 ; n=2$ isolates) was shared between $B$. venosa and $B$. fischeri. No taxa were shared between $B$. venosa and B. olsoniae (Fig. 2). Among the taxa found in $B$. fischeri, eight of them were singletons. $B$. olsoniae and $B$. venosa present five and six singletons, respectively. These results show that each plant host harbors unique endophytes considered rare taxa. In addition, at least one individual of each plant species showed one isolate which was not possible to identify using our polyphasic approach. Such isolates showed low similarity to sequences found in the database. This finding suggests that begonias may harbor new fungal species for science.

The CA was markedly different among all plants species (Fig. 3). Both axes 1 and 2 accounted for 24 and $17 \%$ of the observed variation in these communities, respectively; thus, the remaining $59 \%$ of the difference may be explained by other factors in addition to the plant host. This result may suggest homogeneity between the samples from the same host species.

\section{Discussion}

Here we analyzed the endophytic fungal communities in three Begonia species in the Atlantic Rainforest. Based on culture-dependent methods, we studied the diversity, composition, and structure of fungal communities. Endophyte composition differed among Begonia species, but all presented Colletotrichum as dominant genus. In addition, the structure of endophytes communities was different for each plant species.

In this study, a few genera were abundant in each Begonia species (Table 1). We observed that the B. fischeri endophytic community was more homogenous and with less number of dominant genera than B. venosa and B. olsoniae, as well as $B$. venosa showed less dominant genera than $B$. olsoniae. Variation in endophyte composition among hosts is influenced by quantitative differences in the relative abundance of generalists and the presence or absence of rare taxa [54]. Thus, the patterns of most abundant and rare taxa found

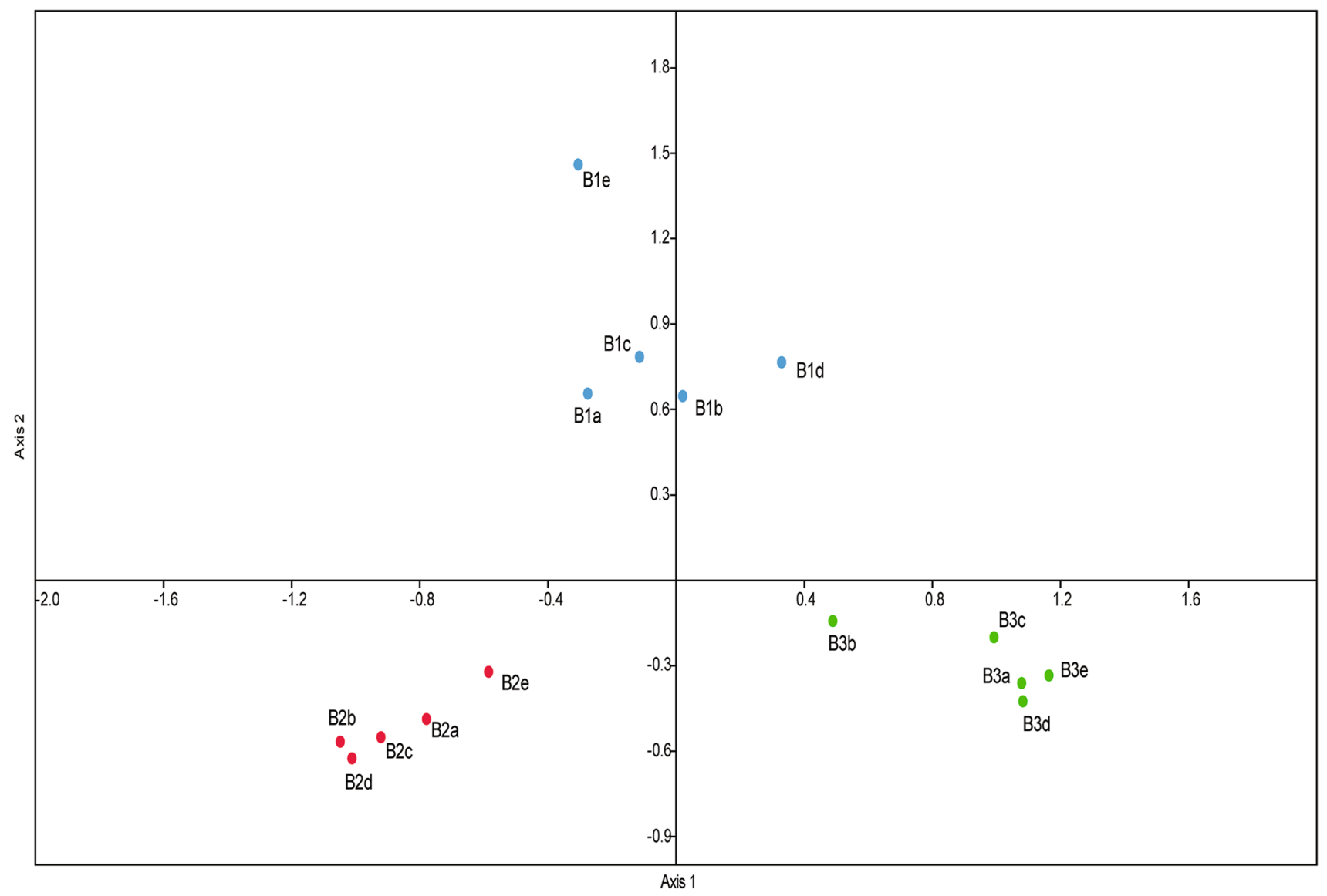

Fig. 3 Structuring of fungal communities in three begonia species (Begonia fischeri, Begonia olsoniae, and Begonia venosa) revealed by correspondence analysis. Figures in axis $1(24 \%)$ and axis $2(17 \%)$ correspond to inertia values. Plant species IDs: B1: B. fischeri, B2: B. olsoniae, B3: $B$. venosa. Letters that follow each plant species represent each individual plants 
in the present study may explain differences in the endophyte community in each Begonia species.

The genus Colletotrichum was the dominant in all begonias. This genus has been isolated with a relatively high frequency from various tropical and temperate hosts including fruit trees and medicinal plants [5, 53]. In addition, Colletotrichum are commonly found in a range of host plants in Brazil as the medicinal Carapa guianensis Aubl. [17], mangrove plants [45], Mangifera indica L. [53], and Eugenia neomyrtifolia Sobral [52], which shows the remarkable flexibility of this fungal genus in host preference.

Diaporthe, the second most abundant genus found in our study may occur as latent pathogens as Colletotrichum [5, 21] but it is also described as a common endophytic fungus $[45,50]$. In addition, in a survey of endophytic fungal communities on wide variety of tropical plant species, Diaporthe occurred in 20 out of 24 host species studied [48]. Like Colletotrichum, the genus Diaporthe is a common endophyte in begonias of this study.

Regarding the genera Epicoccum and Xylaria, these were also found in Pinus halepensis Mill. in Spain [4]. These fungi were reported as producers of active metabolites, for instance, E. nigrum has been reported as common sugarcane endophyte, which is capable of increasing the root system biomass and controlling pathogens in sugarcane from Brazil [16]. Furthermore a series of new compounds, which have antimicrobial or anticancer activities, has been isolated from Xylaria [22, 34].

Endophytes such as Cladosporium, Nigrospora, Neopestalotiopsis, Penicillium, Phyllosticta, Stagonospora, Trichoderma, and other species found in low frequency in this work are also reported as common endophytes [29,35]. Our finds suggests that the endophytic fungal community is shaped by a few genera that are highly represented and by several rare genera represented by only a few members [45]. This result shows that Begonia species harbor a wide range of endophytes in their leaves.

In addition, using the ITS barcode marker for fungal identification some taxa found in the present study could not be identified to the genus level. These taxa are represented as unidentified Ascomycota and Basidiomycota. Also, we assigned one taxon to the Pleosporales order, one taxon to the Cantharellales order, and six taxa belonging to the Xylariales order. Considering that ITS does not resolve species identification in several groups of fungi, our findings reveal that underexplored hosts such as Begonia species are of great importance to discover putative new fungal taxa. These may have new metabolic mechanisms that can be explored for biotechnological purposes.

Although few fungal taxa have been shared among the three plant species, the begonias collected on the continent shared more taxa between them in comparison to $B$. venosa. This result might be related with differences in the collection sites; however, samplings on the continent took place eight months before the sampling on Alcatrazes Island. Furthermore, the expedition carried out in the continental area took place during the winter and the expedition on the island occurred during the summer. Collectively, these factors may also explain the observed differences in shared fungal taxa between begonias from the continent and the island.

Several studies suggest that the endophytic community differs according to the host [30, 37, 51, 60]. However, in these studies the majority of plant hosts were not phylogenetically closely related. Although in the present study the three plant species belong to the same genus, our results showed significant differences between the communities of each host as described by the CA. B. olsoniae and $B$. venosa belong to the same phylogenetic clade [33]. However, these species showed the highest dissimilarity between their communities (83.6\%). That is, the genotypic and phylogenetic relationships of the hosts do not seem to be correlated with the composition of the endophytic community and may differ between hosts of the same species, but may be similar to hosts of other genera or even other families [38].

The observed differences in fungal diversity among plants can also be related to the intrinsic characteristics of each host such as the leaf thickness and abundance of trichomes, which may create a barrier for the entrance of endophytes. For example, B. olsoniae e $B$. venosa have thicker leaves and more trichomes than $B$. fischeri, but we did not find studies on endophytes of such plants that associate these plant features. Furthermore, secondary metabolites present in the leaves of each plant and the fungi interaction in the inside of the leaves can also play a role of selecting the endophytic community.

Understanding the structure of endophytic communities requires the study of a wide range of environmental factors, in addition to the plant host. Here, we show for the first time the community's diversity and structure of endophytic fungi in Begonia species from Atlantic Rainforest. Our results revealed that each Begonia species had its distinct endophytic communities composed of rare and putative undescribed species, and also dominated by common fungal taxa.

Acknowledgements The authors would like to thank "Fundação de Amparo à Pesquisa do Estado de São Paulo (FAPESP)" for providing financial support (Grants \# 2013/50228-8 and 2014/15760-3) and also for a scholarship to the first author (process \# 2014/12021-5). We thank Sergio Birello Sartori for helping during fieldwork, Sergio Kakazu for helping with DNA sequencing, and Dr. Tassio B. de Oliveira for helpful comments on this manuscript. We also thank Prof. Dr. Ludovic Jean Charles Kollmann for the identification of Begonia species. We would like to thank ICMBio for the collecting permits issued to AR (\# 37256-3) and to SPL (\# 21774-1). 


\section{Compliance with Ethical Standards}

Conflict of interest The authors declare that they have no conflict of interest.

\section{References}

1. Araújo WL, Lacava PT, Marcon J, Lima AOS, Sobral JK, Azevedo JL, Pizzirani-Kleiner AA (2010) Guia prático: isolamento e caracterização de microrganismos endofíticos. CALO, Piracicaba

2. Arnold AE, Maynard Z, Gilbert GS, Coley PD, Kursar TA (2000) Are tropical fungal endophytes hyperdiverse? Ecol Lett 3:267-274

3. Arnold AE, Lutzoni F (2007) Diversity and host range of foliar fungal endophytes: are tropical leaves biodiversity hotspots? Ecology 88:541-549

4. Botella L, Diez JJ (2011) Phylogenic diversity of fungal endophytes in Spanish stands of Pinus halepensis. Fungal Divers 47:9-18

5. Cannon PF, Damm U, Johnston PR, Weir BS (2012) Colletotrichum-current status and future directions. Stud Mycol 73:181-213

6. Clarke KR (1993) Non-parametric multivariate analysis of changes in community structure. Aust J Ecol 18:117-143

7. Clarke KR, Gorley RN (2001) PRIMER v.5: user manual/tutorial Primer-E, Plymouth

8. Colwell RK (2013) Estimates: statistical estimation of species richness and shared species from samples. Version 9. User's Guide and application published at http://purl.oclc.org/estimates

9. Davis EC, Shaw AJ (2008) Biogeographic and phylogenetic patterns in diversity of liverwort-associated endophytes. Am J Bot 95:914-924

10. Dewitte A, Leus L, Eeckhaut T, Vanstechelman I, Van Huylenbroeck J, Van Bockstaele E (2009) Genome size variation in Begonia. Genome 52:829-838

11. Dewitte A, Twyford AD, Thomas DC, Kidner CA, Van Huylenbroeck J (2011) The origin of diversity in Begonia: genome dynamism, population processes and phylogenetic patterns. In: Grillo $\mathrm{O}$, Venora $\mathrm{G}$ (eds) The dynamical processes of biodiversity: case studies of evolution and spatial distribution. Rijeka, InTech, Croatia, pp 27-52

12. Dodd SL, Lieckfeldt E, Samuels GJ (2003) Hypocrea atroviridis sp. nov., the teleomorph of Trichoderma atroviride. Mycologia 95:27-40

13. Druzhinina I, Kopchinskiy AG, Komon M, Bissett J, Szakacs G, Kubicek CP (2005) An oligonucleotide barcode for species identification in Trichoderma and Hypocrea. Fungal Genet Biol 42:813-828

14. Ellis MB (1971) Dematiaceous hyphomycetes. Commonwealth Mycological Institute, Kew, Surrey

15. Ellis MB (1976) More dematiaceous hyphomycetes. Commonwealth Mycological Institute, Kew, Surrey

16. Fávaro LCL, Melo FL, Aguilar-Vildoso CI, Araújo WL (2011) Polyphasic analysis of intraspecific diversity in Epicoccum nigrum warrants reclassification into separate species. PLoS ONE 6:e14828

17. Ferreira MC, Vieira MLA, Zani CL, Alves TMA, Sales-Junior PA, Murta SMF, Romanha AJ, Gil LHVG, Carvalho AGO, Zilli JE, Vital MJS, Rosa CA, Rosa LH (2015) Molecular phylogeny, diversity, symbiosis and discover of bioactive compounds of endophytic fungi associated with the medicinal Amazonian plant Carapa guianensis Aublet (Meliaceae). Biochem Syst Ecol 59:36-44
18. Goodall-Copestake WP, Pérez-Espona S, Harris DJ, Hollingsworth PM (2010) The early evolution of the mega-diverse genus Begonia (Begoniaceae) inferred from organelle DNA phylogenies. Biol J Linn Soc 101:243-250

19. Hall TA (1999) BioEdit: a user-friendly biological sequence alignment editor and analysis program for Windows 95/98/NT. Nucl Acids Symp Ser 41:95-98

20. Hammer $\varnothing$, Harper DAT, Ryan PD (2001) PAST: Paleontological statistics software package for education and data analysis. Palaeontol Electron 4:1-9

21. Hata K, Atari R, Sone K (2002) Isolation of endophytic fungi from leaves of Pasania edulis and their within-leaf distributions. Mycoscience 43:369-373

22. Higginbotham SJ, Arnold AE, Ibañez A, Spadafora C, Coley PD, Kursar TA (2013) Bioactivity of fungal endophytes as a function of endophyte taxonomy and the taxonomy and distribution of their host plants. PLoS ONE 8:e73192

23. Hughes M, Hollingsworth PM (2008) Population genetic divergence corresponds with species-level biodiversity patterns in the large genus Begonia. Mol Ecol 17:2643-2651

24. Inderbitzin P, Mehta YR, Berbee ML (2009) Pleospora species with Stemphylium anamorphs: a four locus phylogeny resolves new lineages yet does not distinguish among species in the Pleospora herbarum clade. Mycologia 101:329-339

25. Jacques EL, Mamede MCH (2005) Notas nomenclaturais em Begonia L. (Begoniaceae). Rev Bras Bot 28:579-588

26. Jacques EL (2015) Begoniaceae in Lista de Espécies da Flora do Brasil. Jardim Botânico do Rio de Janeiro. http://reflora.jbrj. gov.br/jabot/floradobrasil/FB5616. Accessed 04 March 2017

27. Katoh K, Standley DM (2013) Mafft multiple sequence alignment software version 7: improvements in performance and usability. Mol Biol Evol 30:772-780

28. Kimura M (1980) A simple method for estimating evolutionary rates of base substitutions through comparative studies of nucleotide sequences. J Mol Evol 16:111-120

29. Kumaresan V, Suryanarayanan TS (2002) Endophyte assemblages in young, mature and senescent leaves of Rhizophora apiculata: evidence for the role of endophytes in mangrove litter degradation. Fungal Divers 9:81-91

30. Lau KM, Arnold AE, Johnson NC (2013) Factors influencing communities of foliar fungal endophytes in riparian woody plants. Fungal Ecol 6:365-378

31. Magurran AE (2004) Measuring biological diversity. Blackwell Science, Oxford

32. Montoya QV, Meirelles LA, Chaverri P, Rodrigues A (2016) Unraveling Trichoderma species in the attine ant environment: description of three new taxa. Antonie Van Leeuwenhoek 109:633-651

33. Moonlight PW, Richardson JE, Tebbitt MC, Thomas DC, Hollands R, Peng CI, Hughes M (2015) Continental-scale diversification patterns in a megadiverse genus: the biogeography of Neotropical Begonia. J Biogeogr 42:1137-1149

34. Mousa WK, Raizada MN (2013) The diversity of anti-microbial secondary metabolites produced by fungal endophytes: an interdisciplinary perspective. Front Microbiol 4:65

35. Nalini MS, Sunayana N, Prakash HS (2014) Endophytic fungal diversity in medicinal plants of western ghats, India. Inter J Biodiver 2014:ID494213

36. Pandikumar P, Babu NP, Ignacimuthu S (2009) Hypoglycemic and antihyperglycemic effect of Begonia malabarica Lam. in normal and streptozotocin induced diabetic rats. J Ethnopharmacol 124:111-115

37. Peršoh D (2013) Factors shaping community structure of endophytic fungi-evidence from the Pinus-Viscum-system. Fungal Divers 60:55-69 
38. Peršoh D (2015) Plant-associated fungal communities in the light of meta'omics. Fungal Divers 75:1-25

39. Petrini O (1991) Fungal endophytes of tree leaves. In: Andrews JH, Hirano SS (eds) Microbial ecology of leaves. Springer-Verlag, New York, pp 179-197

40. Podani J, Miklós I (2002) Resemblance coefficients and the horseshoe effect in principal coordinates analysis. Ecol 83:3331-3343

41. Ramesh N, Viswanathan MB, Saraswathy A, Balakrishna K, Brindha P, Lakshmanaperumalsamy P (2002) Phytochemical and antimicrobial studies of Begonia malabarica. J Ethnopharmacol 79:129-132

42. Sanchez-Azofeifa A, Oki Y, Fernandes GW, Ball RA, Gamon J (2012) Relationships between endophyte diversity and leaf optical properties. Trees 26:291-299

43. Schloss PD, Westcott SL, Ryabin T, Hall JR, Hartmann M, Hollister EB, Lesniewski RA, Oakley BB, Parks DH, Robinson CJ, Sahl JW, Stres B, Thallinger GG, Van Horn DJ, Weber CF (2009) Introducing mothur: open source, platform-independent, community-supported software for describing and comparing microbial communities. Appl Environ Microbiol 75:7537-7541

44. Schoch CL, Seifert KA, Huhndorf S, Robert V, Spouge JL, Levesque CA, Chen W, Fungal Barcoding Consortium (2012) Nuclear ribosomal internal transcribed spacer (ITS) region as a universal DNA barcode marker for Fungi. Proc Natl Acad Sci USA 109:6241-6246

45. Sebastianes FLS, Romão-Dumaresq AS, Lacava PT, Harakava R, Azevedo JL, Melo IS, Pizzirani-Kleiner AA (2013) Species diversity of culturable endophytic fungi from Brazilian mangrove forests. Curr Genet 59:153-166

46. Smith SA, Tank DC, Boulanger LA, Bascom-Slack CA, Eisenman $\mathrm{K}$ et al (2008) Bioactive endophytes warrant intensified exploration and conservation. PLoS ONE 3:e3052

47. Strobel G, Daisy B (2003) Bioprospecting for microbial endophytes and their natural products. Microbiol Mol Biol Rev 67:491-502

48. Suryanarayanan TS, Venkatesan G, Murali TS (2003) Endophytic fungal communities in leaves of tropical forest trees: diversity and distribution patterns. Curr Sci 85:489-493

49. Tamura K, Stecher G, Peterson D, Filipski A, Kumar S (2013) MEGA6: molecular evolutionary genetics analysis version 6.0. Mol Biol Evol 30:2735-2729
50. Udayanga D, Liu X, Crous PW, McKenzie EHC, Chukeatirote E, Hyde KD (2012) A multi-locus phylogenetic evaluation of Diaporthe (Phomopsis). Fungal Divers 56:157-171

51. U'Ren JM, Lutzoni F, Miadlikowska J, Laetsch AD, Arnold AE (2012) Host and geographic structure of endophytic and endolichenic fungi at a continental scale. Am J Bot 99:898-914

52. Vaz ABM, Fontenla S, Rocha FS, Brandão LR, Vieira MLA, Garcia V, Goes-neto A, Rosa CA (2014) Fungal endophyte $\beta$-diversity associated with Myrtaceae species in an Andean Patagonian forest (Argentina) and an Atlantic forest (Brazil). Fungal Ecol 8:28-36

53. Vieira WAS, Michereff SJ, Morais MA, Hyde KD, Câmara MPS (2014) Endophytic species of Colletotrichum associated with mango in northeastern Brazil. Fungal Divers 67:181-202

54. Vincent JB, Weiblen GD, May G (2016) Host associations and beta diversity of fungal endophyte communities in New Guinea rainforest trees. Mol Ecol 25:825-841

55. Walther G, Pawłowska J, Alastruey-Izquierdo A, Wrzosek M, Rodriguez-Tudela JL, Dolatabadi S, Chakrabarti A, Hoog GS (2013) DNA barcoding in Mucorales: an inventory of biodiversity. Persoonia 30:11-47

56. Wanderley MGL, Shepherd GJ, Melhem TSA, Giulietti AM, Martins SE, Romanini RP, Pirani JR, Kirizawa M, Melo MMRF., Cordeiro I, Kinoshita LS (2012) Flora fanerogâmica do estado de São Paulo. Instituto de Botânica, São Paulo

57. Wang B, Yu Y, Wang L (2014) Penicillium fusisporum and $P$. zhuangii, two new monoverticillate species with apical-swelling stipes of section Aspergilloides isolated from plant leaves in China. PLoS ONE 9:e101454

58. Wani ZA, Ashraf N, Mohiuddin T, Riyaz-Ul-Hassan S (2015) Plant-endophyte symbiosis, an ecological perspective. Appl Microbiol Biotechnol 99:2955-2965

59. Wilson D (1995) Endophyte: the evolution of a term and clarification of its use and definition. Oikos 73:274-276

60. Zhang T, Xiang HB, Zhang YQ, Liu HY, Wei YZ, Zhao LX, Yu LY (2013) Molecular analysis of fungal diversity associated with three bryophyte species in the Fildes Region, King George Island, maritime Antarctica. Extremophiles 17:757-765 